\title{
Topographical Relations of the Facial Artery in the Region of the Modiolus Anguli Oris
}

\author{
By \\ Selda ÖNDEROĞLU \\ Assocciate Professor in Department of Anatomy, Hacettepe University, Faculty of Medicine, Ankara, Turkey \\ -Received for Publication, February 10, 1999
}

\begin{abstract}
Key Words: Facial artery, Modiolus, Light microscopy, Human, Cadaver
Summary: The facial artery together with the surrounding tissue in the modiolus was examined under the light microscope. The specimens were obtained from 15 formalin fixed human cadavers in our department. Each specimen was excised as a $1 \mathrm{~cm}^{3}$ cubic mass from the region where the facial artery bisected the line drawn horizontally from the angle of mouth. Light microscopic evaluation of the specimens revealed that the facial artery is surrounded by adipose tissue except one specimen. There was not a fibrous canal nor cleft at the angle of mouth in the modiolus as described.
\end{abstract}

The facial artery, the chief artery of the face, enters the face at the lower border of the mandible anterior to masseter muscle. It runs upward and forward tortuously towards the angle of the mouth, then on the alar base where it, courses along the lateral side of the nose to terminate as the angular facial artery. The course, tortuosity, and diameter of the artery as well as the relationship of the artery to facial mimic muscles, its territory and normal functional anatomy are described well ${ }^{1-6)}$. At the angle of mouth the facial artery courses in the modiolus. Modiolus or modiolus labii is a dense, compact, mobile, fibromuscular mass which consists of interlacing fibers to muscles converging towards or diverging from the angle of mouth. The facial artery courses in the modiolus along its course in perioral region. There is few data about the mode of course of the the facial artery in the modiolus ${ }^{3)}$. During our routine dissections we observed that the artery ran more laterally in the buccal fat. The purpose of this study was to investigate whether the facial artery coursed in a cleft or canal in the modiolus at the angle of mouth.

\section{Materials and Methods}

The material consisted of 15 adult formalin fixed human cadavers. Seven of them were male and eight of them were female. Their ages varied between 44-67 years. None of the cadavers had undergone any surgical procedure prior to resection of the face region. The facial artery is identified bilaterally where it entered the face by hooking around the lower border of the mouth at the anterior edge of the masseter muscle. Control specimens were excised from this region each of which being a $1 \mathrm{~cm}$ cubic mass. The artery was then followed to the angle of mouth by meticulous dissection. The specimens obtained from the region where the artery coursed at the angle of mouth. Approximately $1 \mathrm{~cm}$ cubic mass was excised containing the artery and the surrounding tissue; extending from skin deeply to oral mucosa. The specimens were prepared by routine histologic preparation tecnique. The tissue samples embedded in paraffine blocks were cut $4 \mu \mathrm{m}$ in thickness and they were stained with hematoxilen eosin and verhoff-van gieson ${ }^{7 !}$. These tissue samples were examined under light microscope (Nikon Optiphot, Japan) and their photomicrographs were taken.

\section{Results}

The results of this study showed that the facial artery was not protected by a fibrous cleft or canal in the modiolus at the angle of mouth. Instead there

Correspondence to: Selda Önderoğlu, Ph.D., Department of Anatomy, Hacettepe University, Faculty of Medicine. Ankara, 06100 Turkey. 
was a connective tissue, surrounding the facial artery, facial vein and a branch of the facial nerve, containing small amount of elastic fibers. This envelope was typical to that of a vein, artery and nerve located elsewhere in the body.

In the light microscopic examination of the samples stained with hematoxilen eosin, the endothelium was prominent in some parts of the tunica intima. The subendothelium was normal in light microscopic examination. Internal elastic membrane was observed in all of the specimens. The smooth muscles of tunica media were arranged regularly. Tunica adventitia consisted of loose connective tissue (Fig. 1).

In the light microscopic examination of the samples stained with Verhoff's elastic tissue stain, the internal elastic membrane was observed as black, under the endothelium and subendothelium. The smooth muscle cells of the tunica media were yellow and they showed a regular arrangement. The collagen fibers of tunica adventitia were pink-red and the elastic fibers were black in color. These collagen fibers in the modiolus were loosely arranged and this finding showed that the type of connective tissue was loose connective tissue in this region (Fig. 2).

All the observations mentioned above were as same as the control groups (Figs. 3, 4).

\section{Discussion}

The anatomy of the facial artery in the perioral region has been well described in recent literature ${ }^{6}$, ${ }^{8-12)}$. In his 12 cadaveric specimens Hynes and Boyd (1988) found the facial mimic muscles including the platysma, the outer rim of orbicularis oris, the zygomaticus major and minor, the levator anguli oris and levator labii superioris, superficial to the course of the facial artery in perioral and perinasal regions ${ }^{9}$. Park et al. (1994) studied the branches of the facial artery in perioral region in nine fresh cadavers to propose new perioral arterial flaps. They stated that the facial artery passed at a point between $1.0-2.0 \mathrm{~cm}$ (mean $1.5 \mathrm{~cm}$ ) lateral to the mouth corner ${ }^{10}$. Those authors did not give the relation of the facial artery to the surrounding tissue and structures. In our specimens the facial artery coursed $1.8-2.2 \mathrm{~cm}$ (mean $2.0 \mathrm{~cm}$ ) lateral to the angle of mouth. Stuzin et al. (1990) examined the dimensions of the buccal fat and stated that the anterior limit of the buccal extension of that structure is marked by the facial vessels which were in the same plane as the buccal fat pad; thus the course of the facial artery coincided with the anterior limit of the buccal fat pad $^{13)}$. In our study we observed that the facial artery coursed through the buccal fat pad very near to its anterior limit but did not have a special fibrous canal or cleft.

The plastic surgeons frequently use the facial artery in different type of flaps. Pribaz et al. (1992) combined the principles of nasolabial and buccal mucosal flaps in midfacial reconstruction and designed a new axial musculomucosal flap based on the facial artery. They stressed that to minimize complications, care should be taken to ensure that the flap remains axial, with the facial artery ${ }^{11}$. $\mathrm{Ca}$ macho et al. (1992) stated that in reconstruction of the total upper lip using the fan flaps, the wide pedicle in the commissural angle, must be designed to include the facial artery and the vein ${ }^{12)}$.

None of the studies related to reconstructive surgery did not mention of a cleft or canal of the facial artery at the angle of mouth although the facial artery forms one of the main concern of their surgical procedures. Also there is no data about the existence of that canal in anatomical literature except Gray's Anatomy. In addition to the existence of the fibrous canal or cleft in the modiolus at the angle of mouth Williams et al. (1989) stated that it may prevent the interference of the facial artery with movements of the mimetic muscles ${ }^{3}$.

In the present study, we also observed a typical surrounding tissue characterized by moderate amount of collagen fibers embedded in fatty tissue around the facial artery.

\section{References}

1) Whetzel TP and Mathes SJ. Arterial anatomy of the face: An analysis of vascular territories and perforating cutaneous vessels. Plastic and Reconstructive Surgery 1992; 89 (4):591-605.

2) Lasjaunias $P$, Berenstein $A$ and Doyon D. Normal functional anatomy of the facial artery. Radiology 1979; 133:631-638.

3) Williams PL, Warwick R, Dyson $M$ and Bannister $L H$. Gray's Anatomy. $37^{\text {th }}$ edn. Churchill Livingstone, Edinburgh 1989; pp 578, 736-737.

4) Berkovitz BKB and Moxham BJ. A textbook of head and neck anatomy. Wolfe Publishing Ltd. Barcelona, Spain 1988; pp 161-162.

5) Hollinshead WH. Anatomy for Surgeons, The Head and Neck, Vol. 1, $2^{\text {nd }}$ edn. Harper and Row, Maryland 1969; pp 341-344.

6) Niranjan NS. An anatomical study of the facial artery. Annals of Plastic Surgery 1988; 21(1):14-22.

7) Gridley MF. Manual of Histologic and Special Staining Technics, $2^{\text {nd }}$ edn. Mcgraw-Hill book company inc. 1960; $\mathrm{p} 82$.

8) Midy D, Mauruc B, Vergnes $P$ and Caliot P. A contribution to the study of the facial artery, its branches and anastomoses; application to the anatomic vascular bases of facial flaps. Surgical and Radiologic Anatomy 1986; 8:99-107.

9) Hynes B and Boyd JB. The nasolabial flap. Arch Otolaryngol Head Neck Surg 1988; 114:1389-1391. 
10) Park C, Lineaweaver WC and Buncke HJ. New perioral arterial flaps: Anatomic study and clinical application. Plastic and Reconstructive Surgery 1994; 94(2):268-276.

11) Pribaz J, Stephens W, Crespo L and Gifford G. A new intraoral flap: Facial artery musculomucosal (FAMM) flap. Plastic and Reconstructive Surgery 1992; 90(3):421-429.

12) Camacho F, Moreno JC and Conejo-Mir JS. Total upper lip recunstruction with bilateral fan flaps. J Dermatol Surg Oncol 1992; 18:627-628.

13) Stuzin JM, Wagstrom L, Kawamoto HK, Baker TJ and Wolfe SA. The anatomy and clinical applications of the buccal fat pad. Plastic and Reconstructive Surgery 1990; 85(1):29-37. 
Plate I

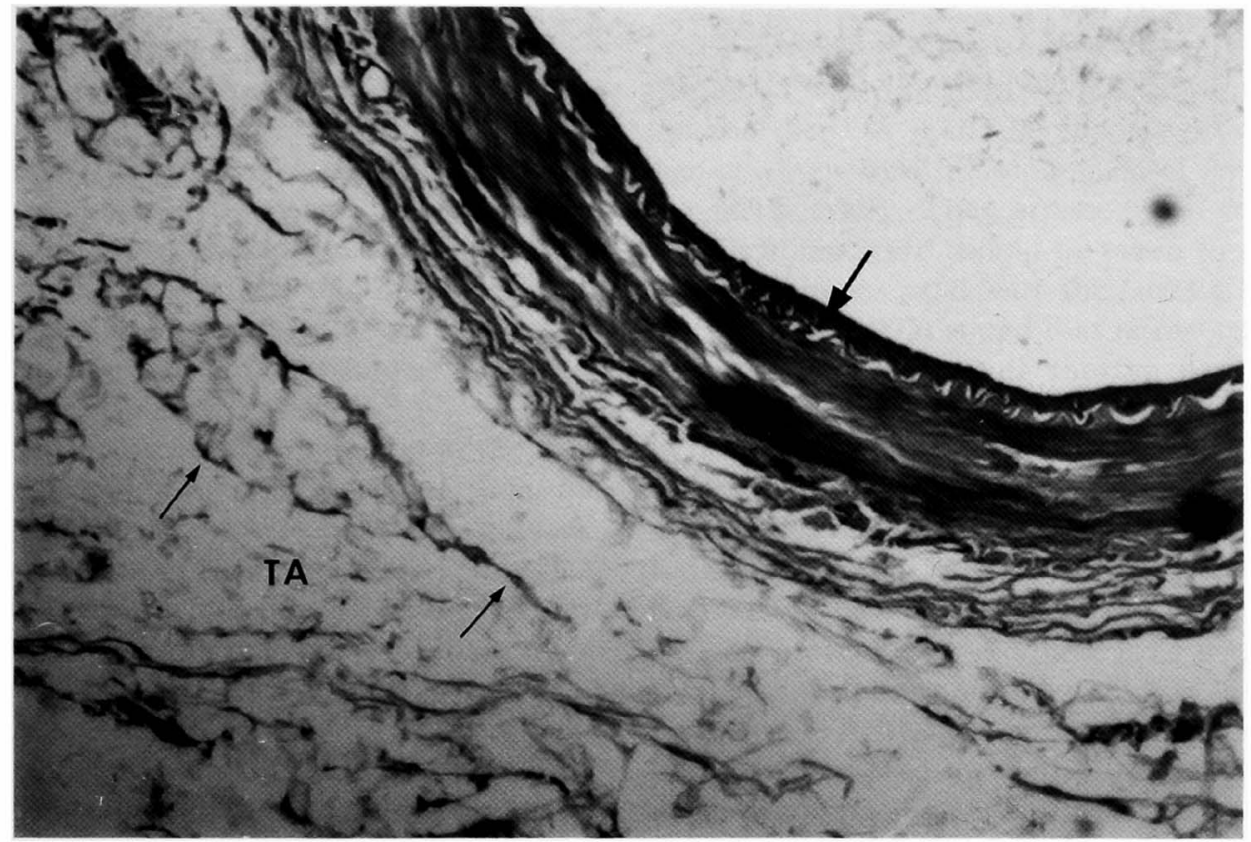

\section{Explanation of Figures}

Plate I

Fig. 1. Segment of a cross-sectioned facial artery. (Hematoxilen eosin, $\times 40$ )

TM: Tunica media

TA: Tunica adventitia

Thin arrow: Collagen fibres Thick arrow: Internal elastic membrane 


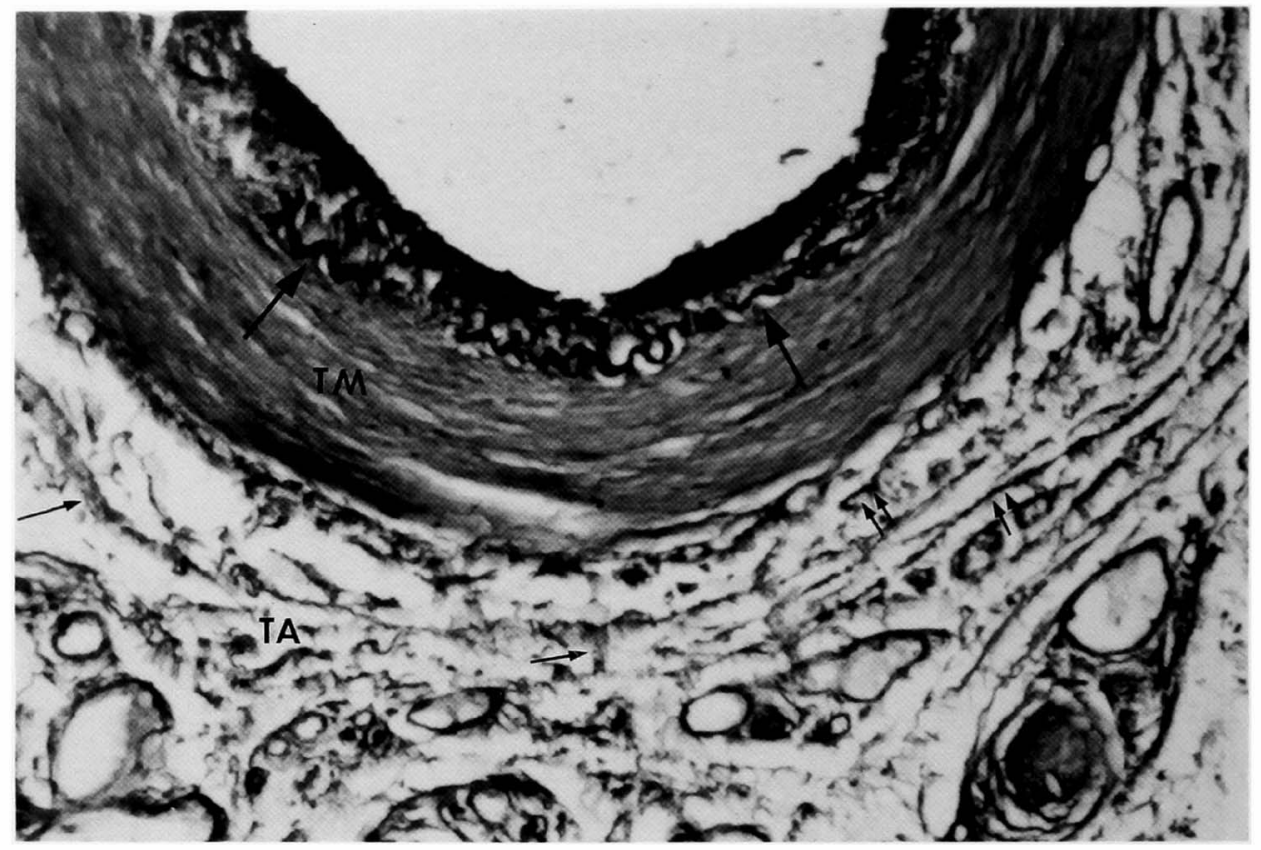

\section{Plate II}

Fig. 2. Segment of a cross-sectioned facial artery. (Verhoff-von gieson, $\times 40$ )

TM: Tunica media

TA: Tunica adventitia

Thin arrow: Collagen fibres

Thick arrow: Internal elastic membrane

Double arrow: Elastic fibres 
Plate III

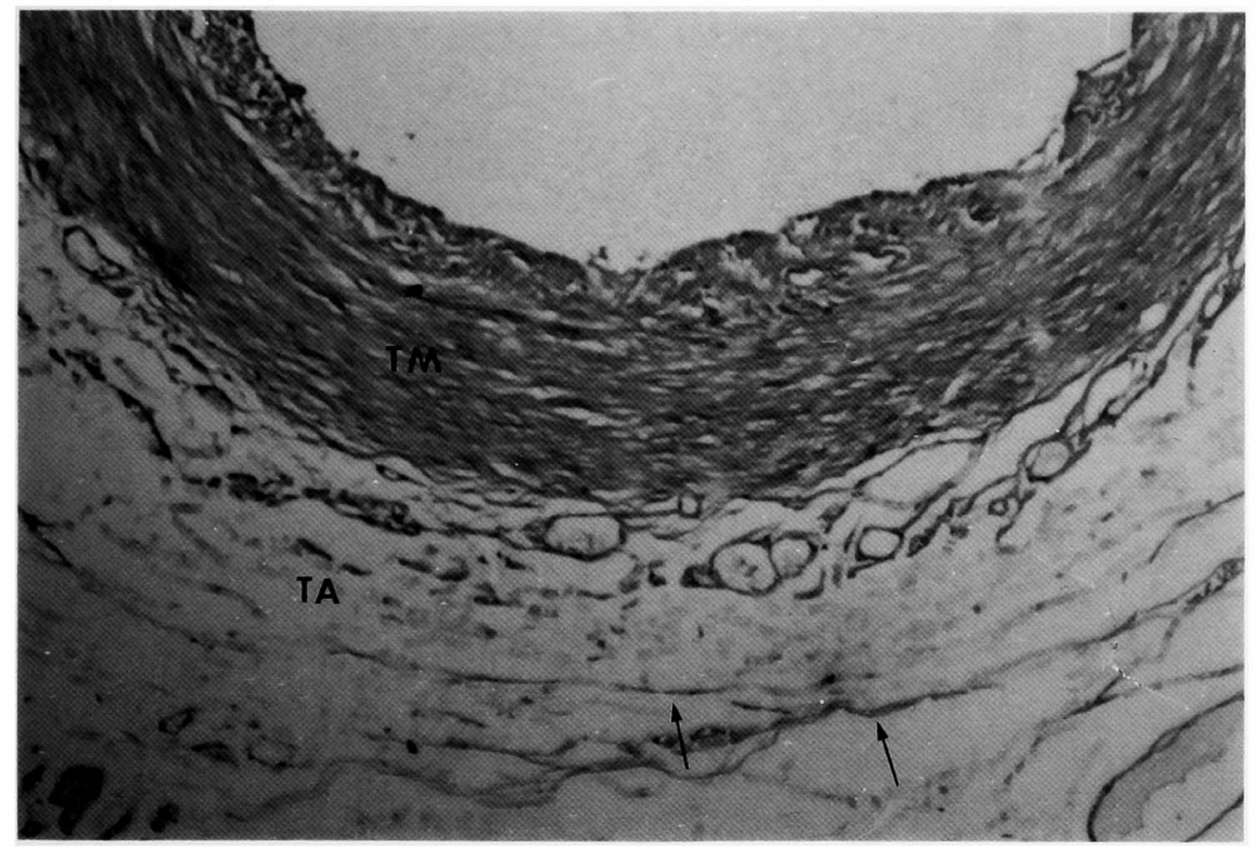

\section{Plate III}

Fig. 3. Segment of a cross-sectioned facial artery of the control specimen. (Hematoxilen eosin, $\times 40$ ) TM: Tunica media

TA: Tunica adventitia

Thin arrow: Collagen fibres 


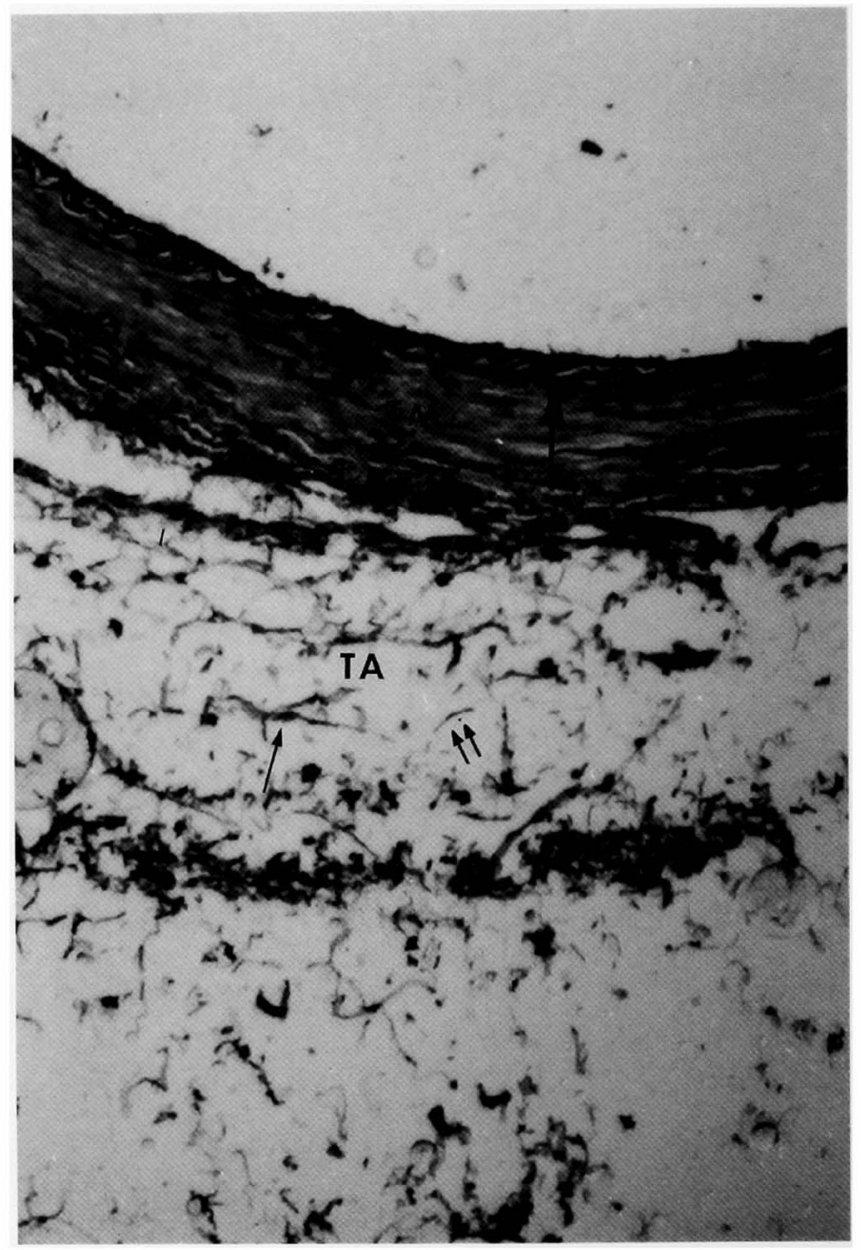

\section{Plate IV}

Fig. 4. Segment of a cross-sectioned facial artery of the control specimen. (Verhoff-von gieson, $\times 40$ ) TM: Tunica media

TA: Tunica adventitia

Thin arrow: Collagen fibres

Thick arrow: Internal elastic membrane

Double arrow: Elastic fibres 